\title{
TKOREAN

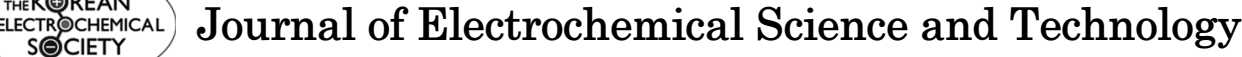 \\ Evaluate of Electrochemical Characteristics in Electrolyzed Reduced Water
}

\author{
Sung-Ho Park ${ }^{\mathrm{a}}$, Su-Jin Yun ${ }^{\mathrm{a}}$, Jeong-Sik Kim ${ }^{\mathrm{b}}$, Hyun-Su Shin ${ }^{\mathrm{b}}$, and Soo-Gil Park ${ }^{\mathrm{a}, \uparrow}$ \\ ${ }^{a}$ Dept. of Industrial Engineering Chemistry, Chungbuk National University, Cheongju 361-763 Korea. \\ ${ }^{b}$ Techwin Co., Korea.
}

\begin{abstract}
:
Active oxygen species or free radicals are considered to cause extensive oxidative damage to biological macromolecules, which brings about a variety of diseases as well as aging. Electrolyzed reduced water(ERW) has been regarded as a ideal antioxidative agent in recent years. ERW is produced by passing a diluted salt solution through an electrolytic cell, within which the anode and cathode are separated by membrane. It can be produced reactive materials in ERW near the cathode during the electrolysis of water. ERW have the following advantages over other traditional cleaning agents: effective antioxidative agent, easy preparation, inexpensive, and environmentally friendly. The main advantage of ERW is its safety and antioxidative effect. ERW with strong reducing potential can be used to remove dirt and grease from items such as cutting boards and other kitchen utensils. The primary aim of this study is the activation mechanism of oxidation reduction potentials, ion conductivity, $\mathrm{pH}$, and electrochemical properties with reactive materials in ERW.
\end{abstract}

Keywords : Oxidation reduction potential, Electrolyzed reduced water, Antioxidant effect

Received April 25, 2011 : Accepted June 29, 2011

\section{Introduction}

Oxidative stress is a condition of imbalance due to excess formation of free radicals and decreased activity of antioxidant defense systems. All oxidative reactions are a continuous source of potentially cytotoxic reactive oxygen species, which play an important role in living systems both through their beneficial and detrimental effects. ${ }^{1)}$ Active oxygen species or free radicals, such as singlet oxygen $\left({ }^{1} \mathrm{O}_{2}\right)$, superoxide anion radical $\left(\mathrm{O}_{2} \cdot{ }^{-}\right)$, hydrogen peroxide $\left(\mathrm{H}_{2} \mathrm{O}_{2}\right)$ and hydroxyl radical $(\cdot \mathrm{OH})$ are considered to cause extensive oxidative damage to biological macromolecules (DNA, membrane and so on), which bring about a variety of disease, as well as aging. ERW is produced by passing a diluted salt solution through an electrolytic cell, within which the anode and cathode

†Corresponding author. Tel.: +82-43-261-2492

E-mail address: sgpark@cbnu.ac.kr are separated by a membrane. Direct current voltage supplied each electrodes respectively, negatively charge ions such as chloride and hydroxide in diluted salt solution move to the anode to give up electrons and become oxygen gas, chlorine gas, hypochlorite ion, hypochlorous acid and hydrochloric acid, while positively charged ions such as hydrogen and sodium move to the cathode to take up electrons and become hydrogen gas and sodium hydroxide. It can be produced reactive materials in ERW near the cathode during the electrolysis of water. ${ }^{2-5}$ ) Two types of electrolyzed solution are produced respectively. Electrolyzed oxidizing water (EOW), with low $\mathrm{pH}(2.3 \sim 2.7)$, high oxidation-reduction potential (ORP, $>1000 \mathrm{mV}$ ), high dissolved oxygen and contains free chlorine is produced from anode side. However, electrolyzed reduced water, with high $\mathrm{pH}(10.0 \sim 11.5)$, high dissolved hydrogen, and low ORP ( -800 to $-900 \mathrm{mV})$, is produced from the cathode side. ${ }^{6-8)}$ The principle of producing electrolyzed water is shown in the Fig. 1 with the following; 


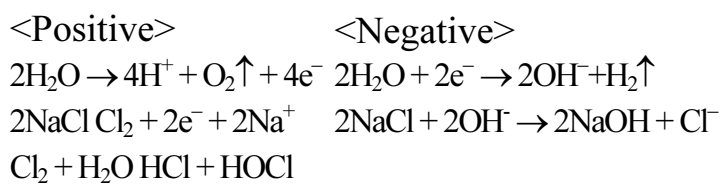

$<$ Positive $>$

$<$ Negative $>$

$2 \mathrm{H}_{2} \mathrm{O} \rightarrow 4 \mathrm{H}^{+}+\mathrm{O}_{2} \uparrow+4 \mathrm{e}^{-} 2 \mathrm{H}_{2} \mathrm{O}+2 \mathrm{e}^{-} \rightarrow 2 \mathrm{OH}^{-}+\mathrm{H}_{2} \uparrow$

$2 \mathrm{NaClCl}_{2}+2 \mathrm{e}^{-}+2 \mathrm{Na}^{+} \quad 2 \mathrm{NaCl}+2 \mathrm{OH}^{-} \rightarrow 2 \mathrm{NaOH}+\mathrm{Cl}^{-}$

$\mathrm{Cl}_{2}+\mathrm{H}_{2} \mathrm{OHCl}+\mathrm{HOCl}$

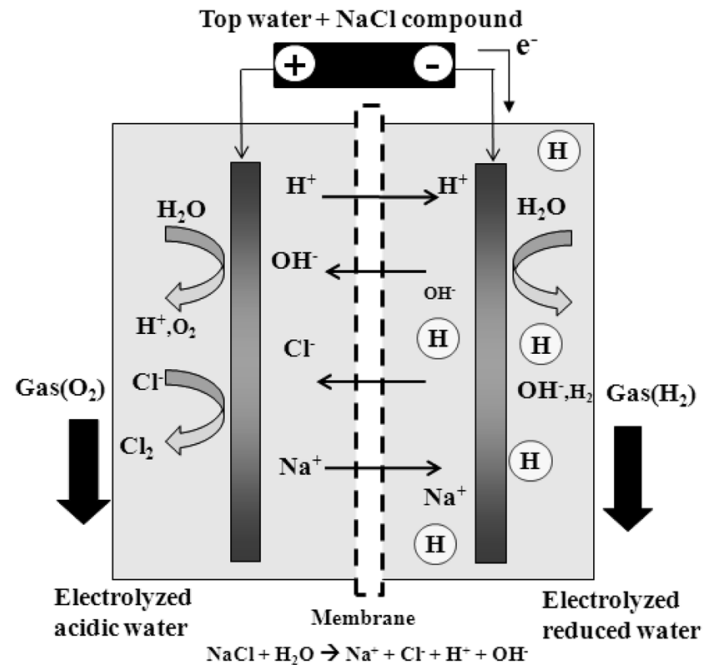

Fig. 1. Schematic diagram of electrolysis system for the ERW producing process.

Although many studies showed that ERW could efficiently suppressed active oxygen in organ, there were few studies on the oxidation reduction potential (ORP) properties, $\mathrm{pH}$, ion conductivity, and its electrochemical properties. ${ }^{9,10)}$ So our study focus on the electrochemical analysis of ERW compared with other alkaline solution.

\section{Experimental}

Electrolyzed reduced water prepared by using a two compartment batch scale electrolysis apparatus with $\mathrm{PtO}_{\mathrm{x}}$ electrode cation membrane. Diluted $\mathrm{NaCl}$ solutions were prepared by dissolving $0.1 \mathrm{wt} \% \mathrm{NaCl}$ in deionized water. The voltage was automatically maintained between 11 and $12 \mathrm{~V}$ of direct current. After electrolysis for $15 \mathrm{~min}$, the anodic solutions, electrolyzed water $(+)$, with a $\mathrm{pH}$ of $2.58 \pm 0.05,50 \pm 5 \mathrm{ppm}$ of available chlorine and ORP $+1100 \mathrm{mV}$ and cathodic solution, electrolyzed water $(-)$, with $\mathrm{pH}$ of $11.8 \pm 0.07$ and ORP -800 to $-900 \mathrm{mV}$ were prepared in the anode and cathode compartment, respectively. Both solutions were prepared immediately before use. Additionally, every 1 minute checked the ORP, $\mathrm{pH}$, ion conductivity to analysis manufacturing properties. Characteristics of the reactive materials investigated by cyclic voltammetry. (CV, IVIUMSTAT, HS Technologies). The oxidation-reduction potential and $\mathrm{pH}$ were measured by an ORP tester (Hand-held $\mathrm{pH} / \mathrm{mV} /$ Temperature/RS 232 Meter, EUTECH Instrument, Malaysia). The ion conductivity was measured by multi-parameter tester (PCSTester, EUTECH Instrument, Malaysia).
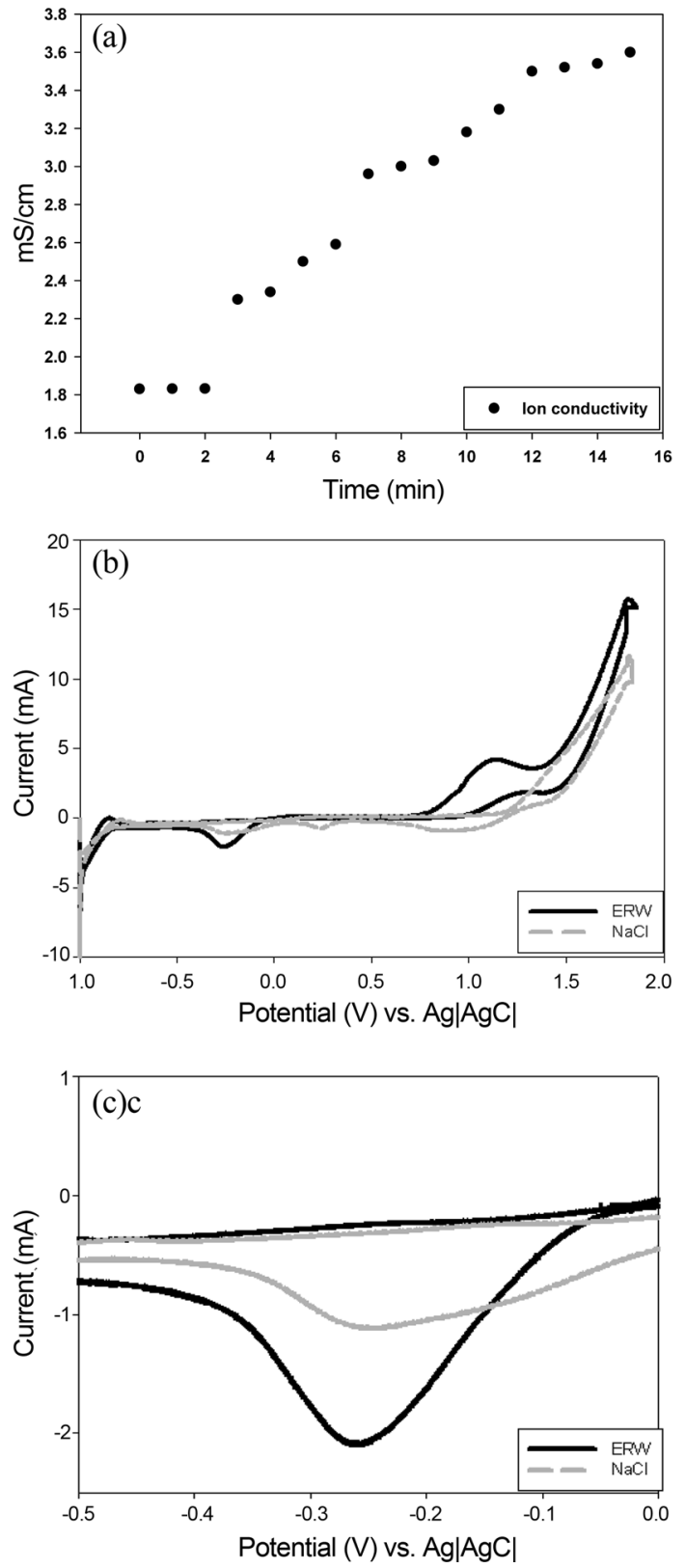

Fig. 2. The relationship of ion conductivity dependent on electrolyzed time. 


\section{Results and discussion}

Fig. 2 shows the change of ion conductivity. In this electrolysis system, reduction occurs at the cathode and oxidation at the anode. Dissociation of $\mathrm{H}_{2} \mathrm{O}$ produces $\mathrm{H}^{+}$and $\mathrm{OH}^{-}$ions. At the cathode, $\mathrm{H}^{+}$ions gain electrons to change into reactive materials. At the anode, $\mathrm{OH}^{-}$ions lose electrons to form $\mathrm{OH}$, which results in the production of $\mathrm{O}_{2}$ and $\mathrm{H}_{2} \mathrm{O}$. When the electron volume is rich, branched chain reaction that radical increases if external energy gives can occur. Equation (1-3) present branched chain reaction. Finally, as time goes, it can be seen that ion conductivity increases as ions increase through electrolysis.

$$
\begin{aligned}
& \cdot \mathrm{OH}+\mathrm{H}_{2} \rightarrow \mathrm{H}_{2} \mathrm{O}+\mathrm{H} \cdot \\
& \mathrm{H} \cdot+\mathrm{O}_{2} \rightarrow \cdot \mathrm{OH}+\cdot \mathrm{O} \cdot \\
& \cdot \mathrm{O} \cdot+\mathrm{H}_{2} \rightarrow \cdot \mathrm{OH}+\mathrm{H} \cdot
\end{aligned}
$$

Fig. 3(A), (B), (C) shows a cyclic voltammogram of ERW and diluted $\mathrm{NaCl}$ solutions were prepared by dissolving $0.1 \mathrm{wt} \% \mathrm{NaCl}$ in deionized water. These results also showed that current density increased by 2 multiples or more. Electrolyzed ions have high ion conductivity than existed ions. Oxidation current density and reduction current density increase by ions that have such high ion conductivity. The ion increase which leads electrolysis improved ion conductivity.

Fig. 4 shows the relationships of $\mathrm{pH}$ dependent on electrolyzed time. $\mathrm{pH}$ values increased as the electrolysis continued. Reaction stagnant started from 6 minute. According as reaction is proceeded, an ion quantity that can move decreases. Ion velocity of propagation also

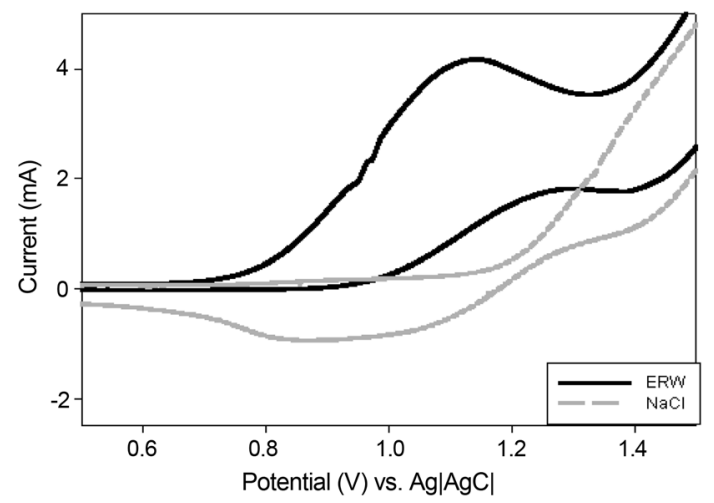

Fig. 3. (A) Cyclic voltammogram of prepared ERW and $0.1 \mathrm{wt} \% \mathrm{NaCl}$ solution at scan rate $0.01 \mathrm{~V} / \mathrm{s}$. The figure indicates values of $\mathrm{V}$ vs. $\mathrm{Ag} \mid \mathrm{AgCl}$. Fig. 3 (B), (C) is magnified (A).

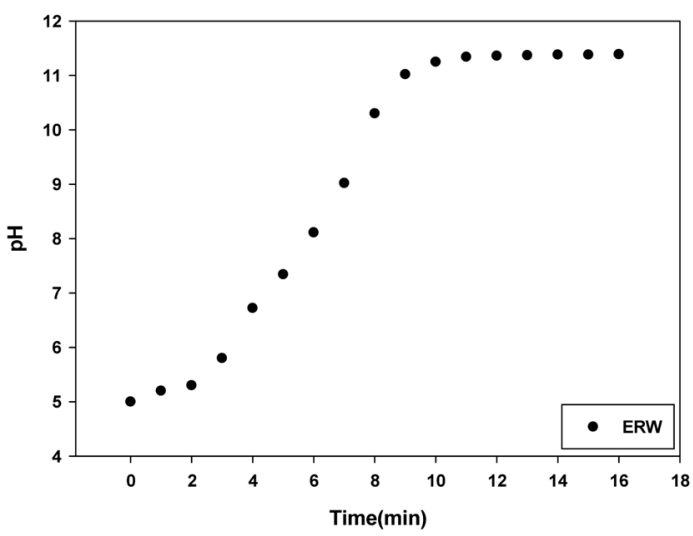

Fig. 4. The relationship of $\mathrm{pH}$ dependent on electrolyzed time.

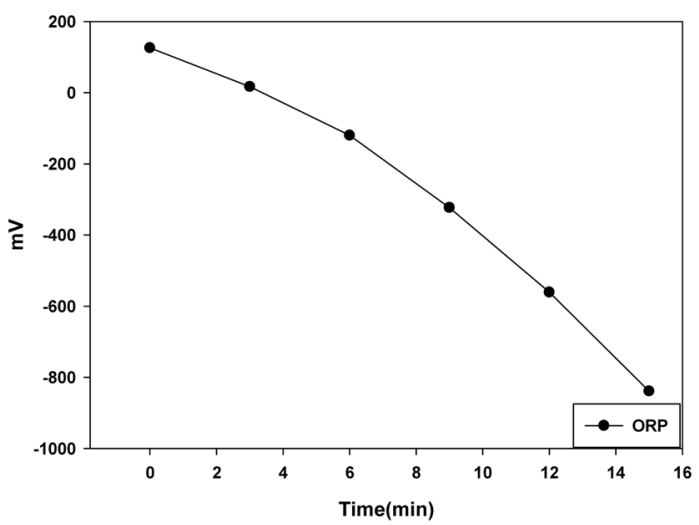

Fig. 5. The relationship of oxidation-reduction potential (ORP) dependent on electrolyzed time.

decreases for these reason. Finally, $\mathrm{pH}$ value is kept holding from 10 minute. This $\mathrm{pH}$ value is almost equal with $\mathrm{NaOH}$ solution. This means that hydrogen ion of quantity which is almost same to ERW and $\mathrm{NaOH}$ solution exists.

Fig. 5 shows the relationships of oxidation reduction potentials (ORP) dependent on electrolyzed time. As time goes, it can be seen that ORP value decreases through electrolysis. But ORP value of $\mathrm{NaOH}$ is keeping steadily. The most significant difference between $\mathrm{NaOH}$ and ERW is that $\mathrm{NaOH}$ has a $200 \mathrm{mV}$ value, while ERW has a value of $-850 \mathrm{mV}$. This implies that the $-850 \mathrm{mV}$ value, the ERW, is water with very strong reducing power. This is a very distinctive and unique value of ERW. And it means that characteristics of ERW can not be explained by $\mathrm{pH}$ only.

In order to investigate for ERW with strong reactivity, a ORP test was conducted. The test was conducted over a 


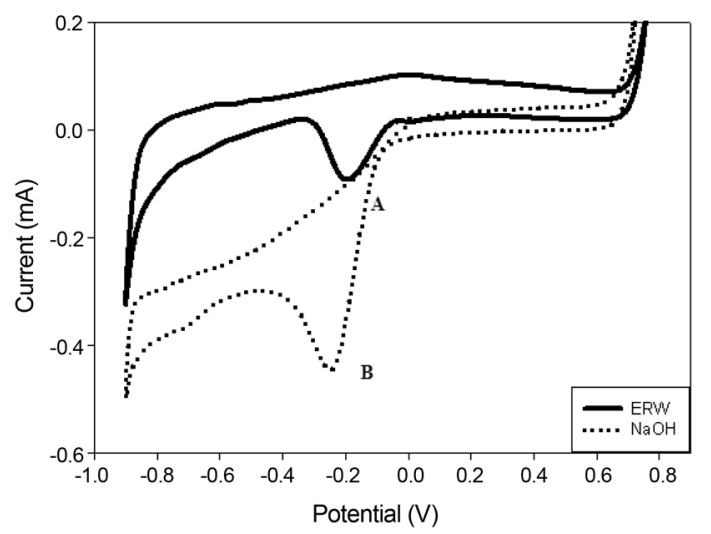

Fig. 6. Cyclic voltammogram of prepared ERW in $0.1 \mathrm{wt} \%$ $\mathrm{NaCl}$ and $\mathrm{NaOH}$ solution at scan rate $0.01 \mathrm{~V} / \mathrm{s}$. The figure indicates values of $\mathrm{V}$ vs. $\mathrm{Ag} \mid \mathrm{AgCl}$.

period of one month, with a plastic bottle which allows gas to penetrate on one side, and a glass bottle on the other. After 1 month later, ORP value of plastic bottle decrease, but the value of glass bottle didn't changed. Reactive materials react with oxygen in plastic bottle. But Two bottles that $\mathrm{NaOH}$ solution includes were stationary. Then, we can think that there is reactive materials like atomic state hydrogen that reactivity is strong to ERW.

Analyzed through cyclic voltammetry in Fig. 6 to confirm existence of reactive materials. Fig. 6 is cyclic voltammogram of $\mathrm{NaOH}$ and ERW. Reduction current density of both $\mathrm{NaOH}$ solution and ERW that have same hydrogen ion in reduction potential should be same. But, reduction current density of two solutions showed difference. This can be thought that is due to reactive materials that exist in solution. These reaction has appeared to equation 4 and 5. Therefore, because of this reactive materials, can think that following two reactions occur in same reduction potential. As a result, Reduction current density of ERW decreased about $0.3 \mathrm{~mA}$ at $0 \mathrm{~V}$.
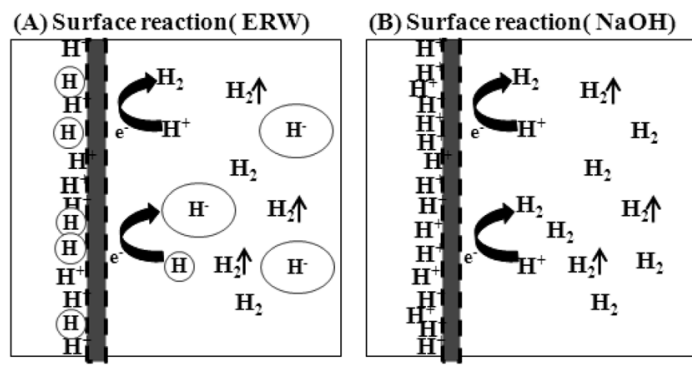

Fig. 7. Schematic of surface reaction at reduction potentials.

$$
\begin{aligned}
& \mathrm{H} \cdot+\mathrm{e} \rightarrow \mathrm{H}^{-} \\
& \mathrm{H}^{+}+\mathrm{e} \rightarrow 1 / 2 \mathrm{H}_{2}
\end{aligned}
$$

Fig. 7 Schematic of surface reaction at reduction potentials. As the $\mathrm{NaOH}$ solution and ERW which both have similar hydrogen ions show different reduction current density at identical potential, we may come to the following conclusion. Because there is reactive materials like atomic state hydrogen with lone-electron in the ERW, when reduction current density is provided, it has a tendency to take a electron and have two electrons on the outmost electronic shell. This competitive reaction on reduction potential between hydrogen ion and reactive materials results in reducing reduction current density.

As we have seen, if reactive materials exists within ERW, $\mathrm{NaOH}$ solution combined at the same ratio would also show a decrease in reduction current density. Such results were confirmed. We could confirmed reduction current
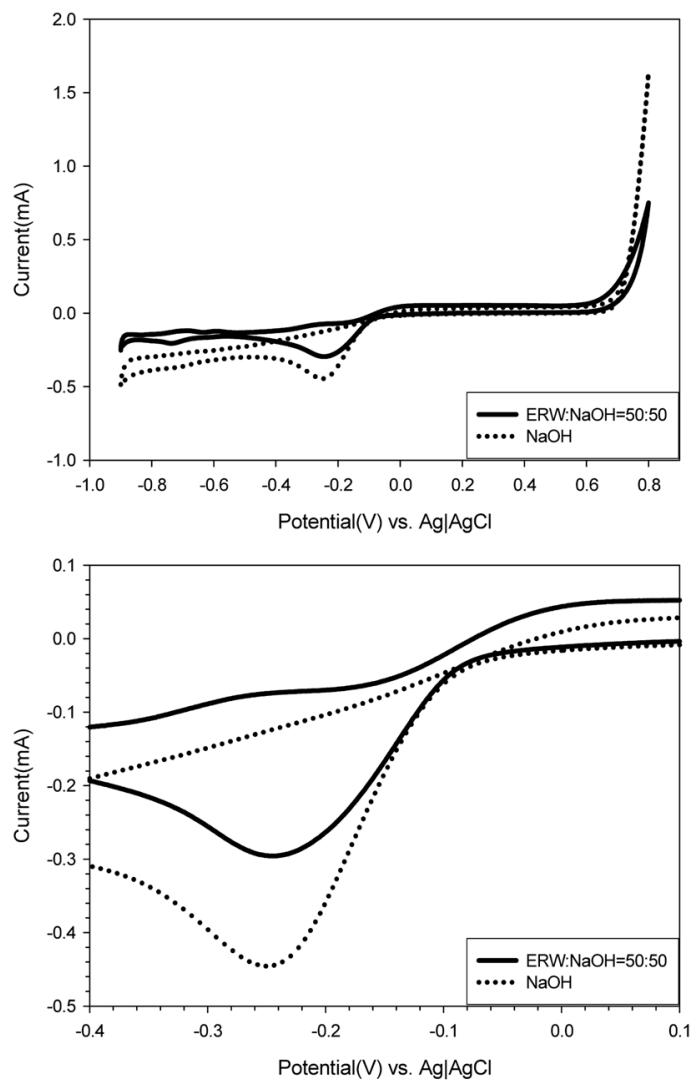

Fig. 8. (A) Cyclic voltammogram of prepared $\mathrm{NaOH}$ solution and $(\mathrm{NaOH}+\mathrm{ERW}$ ratio $1: 1)$ solution at scan rate $0.01 \mathrm{~V} / \mathrm{s}$. The figure indicates values of $\mathrm{V}$ vs. $\mathrm{Ag} \mid \mathrm{AgCl}$. Fig. 8 (B) is magnified (A). 

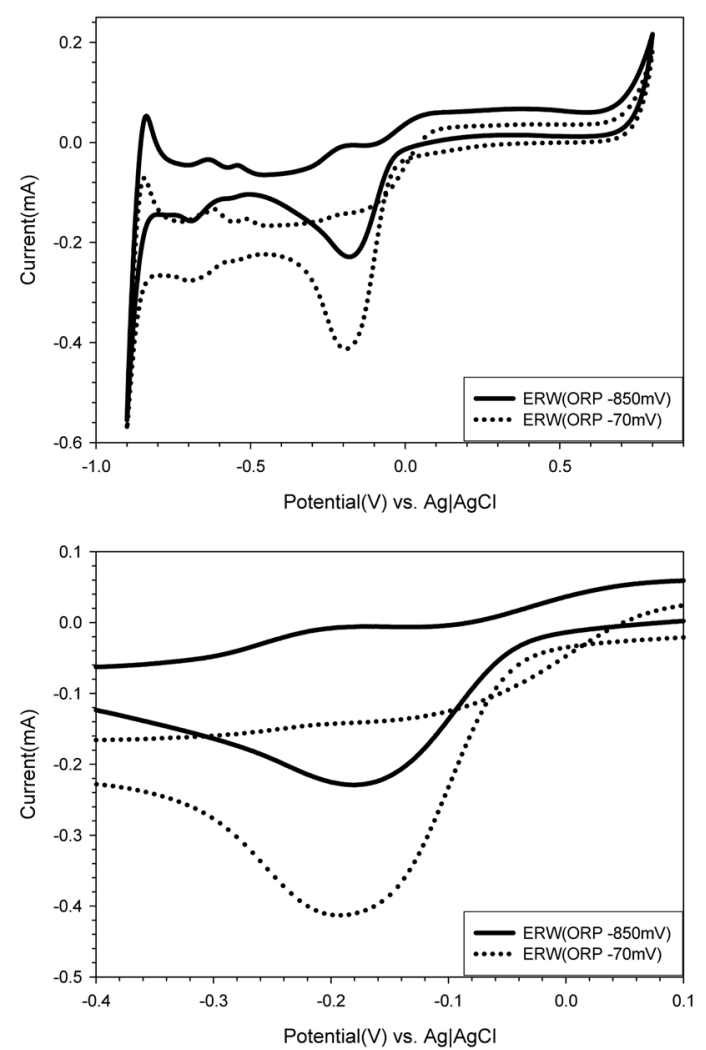

Fig. 9. (A) Cyclic voltammogram of prepared ERW (ORP : $-850 \mathrm{mV}$ ) and ERW(ORP : $-70 \mathrm{mV}$ ) at scan rate $0.01 \mathrm{~V} / \mathrm{s}$. The figure indicates values of V vs. $\mathrm{Ag} \mid \mathrm{AgCl}$. Fig. 9 (B) is magnified (A).

Table 1. ORP Degradation

\begin{tabular}{ccc}
\hline & Glass bottle \\
\hline & Before & After \\
\hline $\mathrm{NaOH}$ & $\fallingdotseq 100 \mathrm{mV}$ & $\fallingdotseq 100 \mathrm{mV}$ \\
$\mathrm{ERW}$ & $\fallingdotseq-857 \mathrm{mV}$ & $\fallingdotseq-780 \mathrm{mV}$ \\
\hline & Plastic bottle \\
\hline $\mathrm{NaOH}$ & Before & After \\
$\mathrm{ERW}$ & $\fallingdotseq 100 \fallingdotseq \mathrm{mV}$ & $\fallingdotseq 98 \mathrm{mV}$ \\
\hline
\end{tabular}

density decreases in graph that measure mixing two solution. Also we can think that reactive materials suppressed reduction of hydrogen ion in $\mathrm{NaOH}$ solution. Fig. 8(A), (B) show that reduction current density decreases about $0.15 \mathrm{~mA}$.
The lined graph indicates newly produced ERW with very low ORP, and the dotted line graph shows a aged ERW which has increased ORP. It can be confirmed that given identical $\mathrm{pH}$ ERWs, the ERW with higher ORP value has more reduction current density. As a result, This competitive reaction on hydrogen ion and reactive materials results in reducing reduction current density, and we can analyze about existence of reactive materials.

\section{Conclusions}

In this research, studied about properties of ERW. The ERW from the cathode obtained By electrolysis sodium chloride solution, was confirmed to have not only hydrogen ion but also reactive materials like atomic state hydrogen. We conducted ORP and Cyclic voltammetry analysis to study property of reactive materials. ERW show very negative ORP value, and this was due to reactive materials. Through an ORP decrease experiment, reactive materials that exist in ERW could confirm which reactivity is strong. The existence of reactive materials could be confirmed through the Cyclic voltammetry method. reactive materials suppressed reduction of hydrogen ion in same reduction potential. It was due to competitive reaction between reactive materials and hydrogen ion. This competitive reaction on reduction potential between hydrogen ion and reactive materials results in reducing reduction of hydrogen ion. As a result, reduction current density was reduced. Through this cyclic voltammetry and ORP experiment, we can confirm existence of reactive materials in ERW. Also, It seems possible to quantitatively analyze the amount of reactive materials like atomic state hydrogen existing in the ERW by using this method.

\section{Acknowledgment}

This research was financially supported by the Ministry of Coomerce, Industry and Energy (MOCIE) and Korea Industrial Technology Foundation(KOTEF) through the Human Resource Training Project for Regional Innovation.

\section{References}

1. Mi-ja Kim and Hye Kyung Kim, Life science, 79, 2288 (2006).

2. S. sanetaka, K. shigeru, N. Mariko, M. Takumi, K. Kenichi, G. Miho, H. Hidemitsu and O. Kazumichi, B. B research communications, 234, 269 (1997).

3. H. Yu-Ru, H. Yen-Con, H. Shun-Yao, H. Yao-Wen and H. deng-Fwu, Food Control, 19, 329 (2008). 
4. H. Kokichi, S. Dongxu, L. Richard, K. Yoshinori and F. Gabriel, Biophysical Chemistry, 107, 71 (2004).

5. T. Chia-Fang, H. Yu-Wen, C. Wen-Kang, C. Wen-Huei, Y. Cheng-Chieh, H. Yung-Chyuan and L. Fung-Jou, Food and Chemical Toxicology, 47, 2031 (2009).

6. H. S.Y, J. Food Engineering, 60, 469 (2003).

7. H. Shun-Yao and K. Hsiao-Yuan, J. Food Engineering, 65, 465 (2004).
8. H. shun-Yao, J. Food Engineering, 66, 171 (2005).

9. M. Chizuko, S. Kouichi, M. Shinichi, K. Hiromasa, G. Toshiyuki, K. Takehiro, H. Wu, M. Hirofumi, I. Atsuo, N. Yoshiko, T. Masami, Y. Osamu, S. Hiromitsu, M. Toyoyuki and K. Yoji, J. Virological Methods, 85, 163 (2000)

10. L. Long B, C. Wei $\mathrm{M}$ and X. Chen M, J. Food Engineering, 78, 1326 (2007). 